\title{
O poema "Tigre", de Inuhiko Yomota, e a estrutura polifónica da percepção artística
}

\author{
The poem “Tiger” by Inuhiko Yomota and the polyphonic structure of the artistic \\ perception \\ Olga Donata GUERIZOLI KEMPINSKA* \\ Universidade Federal Fluminense (UFF)
}

\begin{abstract}
RESUMO: Ao encenar a experiência criativa enquanto um jogo com a multiplicidade de referências culturais e com a instabilidade formal, o texto "Tigre" do poeta japonês Inuhiko Yomota traz as reminiscências das inquietações em torno ao sentido da linguagem poética também em seus aspectos estéticos, que envolvem o ato da leitura. A ênfase dada à intensidade do movimento da precipitação do objeto simbólico participa, por sua vez, do resgate da herança dos primórdios do barroco, remetendo, com isso, à encenação poética de um aparente caos espiritual, que confirma a teoria da criatividade baseada na polifonia da percepção artística.
\end{abstract}

PALAVRAS-CHAVE: Metalinguagem. Intertextualidade. Criatividade. Poesia japonesa.

\begin{abstract}
In staging the creative experience as a play with the multiplicity of cultural references and with the formal instability, the text "Tiger" by the Japanese poet Yomota Inuhiko brings the reminiscences of the concerns around the sense of the poetic language also in its aesthetic aspects, involving the act of reading. The emphasis given to the intense movement of precipitation of symbolic object participates in the rescue of the heritage of the early Baroque, referring to the representation of an apparent spiritual chaos, which confirms the theory of creativity based on the affirmation of the polyphony of artistic perception.
\end{abstract}

KEYWORDS: Metalanguage. Intertextuality. Creativity. Japanese Poetry.

A instigante relação que se tece entre a criação poética e a animalidade, e que encontrou seu âmbito privilegiado no resgate dos elementos do barroco em diversas teorias da segunda metade do século XX, possui uma grande eficácia argumentativa.

\footnotetext{
${ }^{*}$ Doutora - UFF - Universidade Federal Fluminense - Instituto de Letras - Departamento de Ciências da Linguagem - Niterói - RJ - Brasil - 24020-006- olgagkem@gmail.com 
Seus aspectos viscerais e angustiantes, que remetem à dificuldade e aos riscos da tarefa criativa, configuram a encenação da imagem do tigre, que se tornou o centro do interesse de muitos poetas e encontrou recentemente sua reafirmação no trabalho tradutório da revista catalã sèrieAlfa na forma da coletânea de mais de dois mil textos provenientes de diferentes âmbitos linguísticos e culturais. O tema da presente reflexão é justamente a investigação teórica dessa eficácia, e seu objeto, o poema "Tigre" de Inuhiko Yomota, publicado em 2014 no volume intitulado Meu purgatório, わが煉狺 (Waga rengoku).

Traduzir um poema a partir de duas versões, escritas nas línguas tão diferentes como o japonês e o inglês, é uma tarefa falsamente fácil. A facilidade é aqui, de fato, apenas aparente, pois o desdobramento do original em vez de tornar o texto mais disponível força o tradutor a um vai-e-vem linguístico potencialmente interminável. No Brasil bem o sabem, por exemplo, Paulo Leminski (1986) e Ana Helena Souza (2014), que se aventuraram nas versões de Malone morre, trazendo como frutos de sua tarefa versões muito diferentes, a primeira, desenvolta, a segunda, relutante. A muito debatida questão da "fidelidade ao texto" (ADORNO, 2003, p. 151), vinculada à dificuldade do original, vê-se deslocada para o âmbito da prática dos limites.

O texto “Tigre” do poeta Inuhiko Yomota (Yomota Inuhiko 四方田犬彦), que recentemente verteu para o japonês $A$ obscena senhora $D$ e Com os meus olhos de cão (2017), expõe o tradutor a uma dificuldade suplementar, relacionada a um intenso trabalho de referências intertextuais:

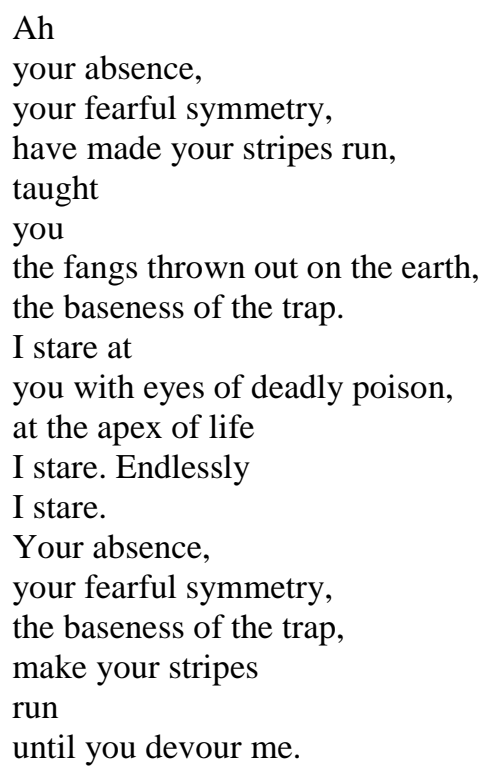


(YOMOTA, 2015, p. 30)

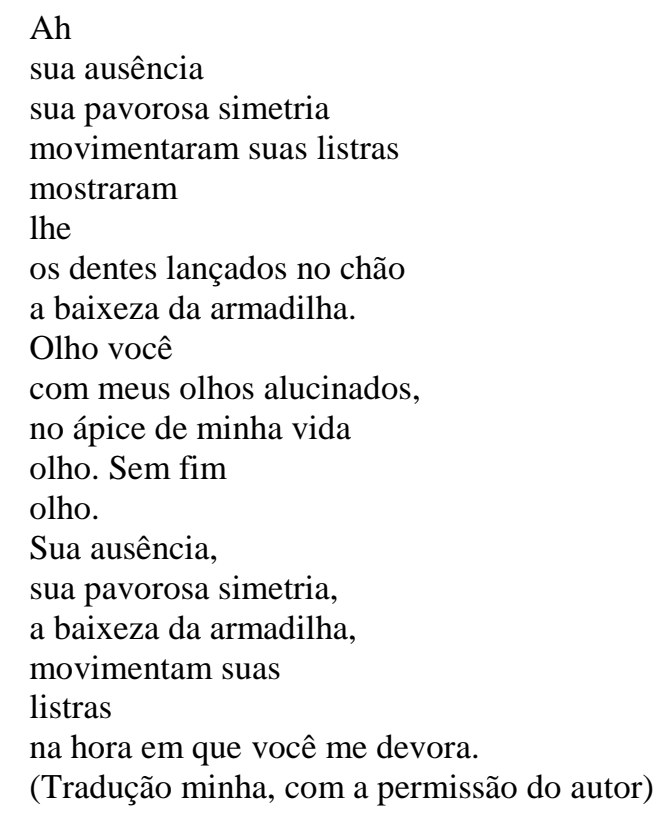

O poema assinala a referência ao texto "O tigre ausência" de Cristina Campo, dedicado ao pai e à mãe ${ }^{1}$. A interjeição inicial pode ser comparada a um dos procedimentos do haikai, a saber, à partícula kana, que garante a eficácia do "núcleo em torno do qual se constela a energia poética” (FRANCHETTI, 1996, p. 33). Transportada para o início, a interjeição coloca em relevo as experiências da ausência e da angústia suscitada pela simetria e, ao mesmo tempo, traz a impressão, reforçada pela repetição, da possibilidade de se operar uma dobra semântica o texto.

"Desde que passamos a pensar em termos de vontade e desejo, ficamos batendo contra as grades de uma prisão" (FRY, 1969, p. 47). Relacionada ao texto de William Blake comentado no estudo de Northrop Fry (1969), que também lança mão de uma estrutura cujo final longe de arrematar, sugere um movimento de retorno, a "simetria" remete, de fato, à experiência da intensa angústia, que deve ser compreendida como a ansiedade relacionada ao próprio processo da criação poética:

Tigre, tigre, flamante fulgor

Nas florestas de denso negror,

Que olho imortal, que mão poderia

Te moldar a feroz simetría?

Em que altura ou abismo sem par

\footnotetext{
${ }^{1}$ CAMPOS, Cristina. La tigre assenza. Disponível em: https://seriealfa.com/tigre/tigre8/campo.htm. Revista Moara, n. 52, jan-jul 2019 ISSN: 0104-0944 
Ardeu o fogo de teu olhar?

Com quais asas sobre ele ao que clama?

Quais as mãos que seguram a chama?

Qual ombro poderia, ou qual arte,

Essas fibras do peito forjar-te?

E, ao pulsar desse teu coração,

Que pés horrendos, que horrenda mão?

Qual o martelo? Qual a corrente?

Qual fornalha fundiu tua mente?

Qual a bigorna? Os punhos são quais,

Que atenazam terrores mortais?

Quando os astros, inermes de espanto, Salpicaram os céus com seu pranto,

Por acaso sorriu teu obreiro?

Quem te fez, fez também o Cordeiro?

Tigre, tigre, flamante fulgor

Nas florestas de denso negror,

Que olho imortal, que mão ousaria

Te moldar a feroz simetría?

(BLAKE, 1993, p. 55)

Tyger! Tyger! burning bright

In the forests of the night,

What immortal hand or eye

Could frame your fearful symmetry?

In what distant deeps or skies

Burnt the fire of thine eyes?

On what wings dare he aspire?

What the hand dare sieze the fire?

And what shoulder, \& what art,

Could twist the sinews of thy heart?

And when thy heart began to beat,

What dread hand? \& what dread feet?

What the hammer? what the chain?

In what furnace was thy brain?

What the anvil? what dread grasp

Dare its deadly terrors clasp?

When the stars threw down their spears, And water'd heaven with their tears,

Did he smile his work to see?

Did he who made the Lamb make thee?

Tyger! Tyger! burning bright In the forests of the night, What immortal hand or eye Dare frame your fearful symmetry?

(BLAKE, 1958, p. 49-50) 
O tradutor brasileiro sugere "a identificação do Tigre com a Energia Primitiva e com o Inferno" (AUTOR, ano apud BLAKE, 1993, p. 111), evocando também a comparação entre o animal selvagem e Cristo. A forma do cristianismo de Blake parece ter sido herética no sentido gnóstico "pelo fato de ter identificado Cristo o filho com a completude da bondade espiritual, tendo feito de Deus o pai o símbolo do terror e da tirania." (AUTOR, ano apud. BLAKE, 1958, p. 11). Decorre dessa crença a exasperação da representação das situações de fortes contrastes e de oposições antagónicas, como também um jogo com a irregularidade, assinalado na forma da falsa rima eye symmetry, que constituem um resgate das formas do barroco.

No imaginário dos inícios do barroco que insiste na veemência da desordem interior do ser humano, Cristo corresponde, com efeito, às imagens da luz "geralmente relacionadas com a estabilidade, a eternidade, a virtude" (BŁOŃSKI, 2001, p. 46). No poema de Yomota a simetria - um dos elementos da estrutura harmoniosa da estética clássica - é descrita como pavorosa. Ela parece ultrapassar, com isso, o domínio da estética para ingressar no da oposição entre o bem e o mal, deslocando-se em seguida para o âmbito da psicologia da criação.

A experiência de uma intensa solidão provoca uma colocação à margem da realidade e o enclausuramento do sujeito no universo das abstrações caracterizado por uma "precipitação do objeto simbólico" (BŁOŃSKI, 1969, p. 54). A ênfase dada à intensidade de um tal movimento também participa do resgate da herança dos primórdios do barroco, remetendo, com isso, à encenação poética de um caos espiritual.

Ao elaborar em 1915 a estrutura das oposições de cinco categorias estilísticas, Heinrich Wölfflin reconhece no barroco a predileção pelo pictural em seus aspectos de uma "aparência flutuante" (WÖLFFLIN, 1952, p. 16), pela forma aberta, dinâmica e em tensão que faz com que "a obra transborde por assim dizer em todas as direções, impaciente com qualquer limite" (WÖLFFLIN, 1952, p. 139), pela unidade e pela clareza relativa. Se a arte clássica privilegiava o rigor da simetria e, com isso, a oposição entre a verticalidade e a horizontalidade, o barroco subverte a estabilidade do eixo central, insistindo, antes, no movimento oblíquo e criando destarte o efeito de um “equilíbrio em suspense” (WÖLFFLIN, 1952, p. 145). A construção atectónica associase à rejeição da multiplicidade de cores, substituída pelas relações entre tons. A exasperação do instante - no poema que é objeto da presente reflexão, a acentuação da 
figura principal do tigre - tem um efeito totalizador. Prioriza-se também a dificuldade e a obscuridade, que anunciam a estética do sublime de Burke de 1756. Sendo a emoção mais forte da qual o espírito humano é capaz, o sublime relaciona-se, de fato, com a dificuldade da compreensão, pois "as imagens criadas pela poesia pertencem sempre a esse tipo obscuro" (BURKE, 1993, p. 87). 
お 罠 地 斑 畏 不 あ虎

まの上紋る在あ

え

卑にをべが

にし役走き

さげら物

を出せ衝

さ が

れ

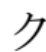

た

リ

牙

ス

チ

を

ナ

力

ノ

ポ

に

倣

い

$\tau$ 
わ走罠畏不見見お生劇教

たらのる在つつまの薬え

しせ卑べがめめえ頂のた

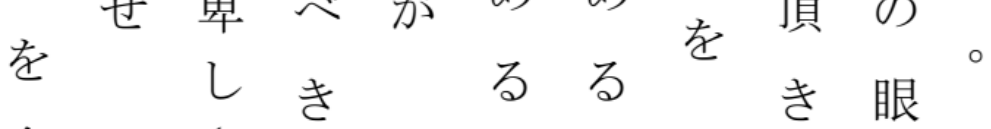

食さささ。眼

りを物。に差わ

喰

衝

ら斑 が

い

した

ら亦は は

う紋

で見

とをも

き

め

ま

る

で

○

(YOMOTA, 2014, p. 42-43). 
Significativamente, ao se debruçar sobre as diferenças existentes na arte do retrato, Wölfflin assinala que a poética barroca "tem como seu conteúdo antes o olhar do que o olho, e antes a boca do que a palavra que dela sai” (WÖLFFLIN, 1952, p. 262). Notemos ainda de passagem que no ensaio de Gilles Deleuze - um dos teóricos do retorno dos traços do barroco na contemporaneidade -, sobre Filme de Beckett (ano), a dimensão inquietante e alucinante do olhar é descrita em termos da produção dos efeitos da experiência do "inconsciente ótico" (BENJAMIN, 1996, p. 189), tal como vislumbrada por Walter Benjamin, ou seja, da impressão da precipitação do visível e de uma insuportável e inevitável reciprocidade, na qual "toda percepção como tal é percepção de percepção" (DELEUZE, 1997, p. 37).

No poema de Yomota (ano) a simetria, o grande apanágio da estrutura da arte clássica, desloca-se para o âmbito da relação estética, remetendo também à experiência do contraste entre a página branca e as listras do texto, cujo incapturável movimento - o da escrita e o da leitura - desemboca na emergência de sentidos. Essa interpretação encontra um respaldo no poema de Blake, que, além de evocar o contraste entre a luz e a escuridão, encena sua relação violenta com o "olho" e a "mão", evocando, com isso, o jogo entre a visão e o tato.

O ideograma 劇, que significa, entre outros, “teatro", compartilha com o ideograma 虎, “tigre” (mas também “embriagado”), a radical 虐, que possui o sentido de "tigrado". No poema "Tigre" o ideograma 劇 entra em combinação com o ideograma 薬 para compor a palavra 劇薬, que pode significar tanto “forte veneno", quanto "poderoso remédio", aproximando-se do complexo jogo de sentidos desconstrucionista em torno ao vocábulo "phármakon" no pensamento de Derrida (2005), e tocando, assim aos impasses das tentativas da reconciliação dos efeitos da escrita com os da imagem. No mito da rejeição da escrita, seu inventor Theuth corresponde, de fato, à figura do filho e à figura de uma divindade subalterna, uma vez que seu pai remete ao sol, à clareza e à vida, enquanto ele mesmo se vê associado à lua, à escuridão e à morte. Ao deslocar o embate criativo entre o animal e a floresta, manifesto em Blake, para a forma do próprio tigre em seus aspectos centrífugos, transgressores das estruturas do universo clássico, o poema de Yomota insiste também na violência do indispensável elemento dionisíaco (NIETSCHE, 2007): 


\section{劇
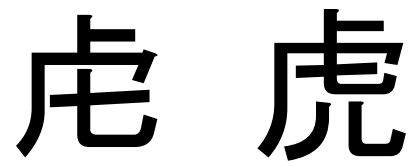

Em sua teoria da arte fundamentada na visão psicanalítica da criação Anton Ehrenzweig contrapõe-se em 1967 às afirmações da falta de estrutura no nível profundo da apreensão, na qual "não haveria distinção alguma entre os opostos" (EHRENZWEIG, 1974, p. 30). Longe de ser incoerente e caótico, esse nível remete às formas indiferenciadas da percepção. Assim, trata-se, antes, "de um instrumento de precisão para um scanning criador muito superior à razão e à lógica discursivas." (EHRENZWEIG, 1974, p. 39), que desemboca na experiência da dificuldade da compreensão, frequentemente denominada "obscuridade" e que traz curiosos ecos da teoria burkeana do sublime.

Ao valorizar a percepção criativa, Ehrenzweig insiste em sua teoria da criatividade no caráter fortemente polifônico de qualquer estrutura artística, situando, com isso, os processos criativos no âmbito da atenção difusa. Eles se tornam, de fato, inseparáveis do complexo estado emocional conhecido como "angústia" que, desprovido de qualquer finalidade real e concreta, e associado sobretudo à experiência da espera, constitui a maneira de "defender-se do medo" (FREUD, 1969, p. 382), sendo também facilmente intercambiável por outros afetos.

Ao encenar a experiência criativa enquanto um jogo com a multiplicidade de referências e com a instabilidade formal, o poema "Tigre" traz as reminiscências das principais inquietações em torno ao sentido da linguagem poética também em seus aspectos estéticos e transculturais, que envolvem os aspectos materiais do ato da leitura, assim como o movimento de sua interpretação.

De fato, o desdobramento da atenção leitora atraída pelos dados visuais de um signo e, ao mesmo tempo ansiosa para totalizar seu sentido sempre em fuga, presente no fazer poético de Blake que fazia das artes visuais um contraponto de seus versos, encontrou sua formulação teórica na época formalista, em 1918 no pensamento de Ernest Fenollosa e de Ezra Pound (1977), como também nas primeiras elaborações da teoria da montagem por Sierguéi Eisenstein (apud DE CAMPOS, 1993, p. 149-166) 
fascinadas pela possibilidade da produção da diferença qualitativa irredutível a uma simples adição quantitativa dos elementos de um acontecimento semiótico.

\section{REFERÊNCIAS}

ADORNO, T. Notas de Literatura I. Tradução J. de Almeida. São Paulo: Editora 34, 2003.

BECKETT, S. Malone morre. Tradução P. Leminski. São Paulo: Brasiliense, 1986.

BECKETT, S. Malone morre. Tradução A. H. Souza. São Paulo: Globo, 2014.

BENJAMIN, W. Magia e técnica, arte e política. Tradução S. P. Rouanet. Rio de Janeiro: Brasiliense, 1996.

BLAKE, W. A Selection of Poems and Letters. Introducão Bronowski, J. Nova Iorque: 1958.

BLAKE, W. Poesia e prosa selecionados. Tradução P. Vizioli. São Paulo: Nova Alexandria, 1993.

BŁOŃSKI, J. Mikołaj Sẹp Szarzyński a początki polskiego baroku. Cracóvia: Universitas, 2001.

BURKE, E. Uma investigação filosófica sobre a origem de nossas ideias do sublime e do belo. Tradução E. A. Dobránszky. Campinas: Ed. da UNICAMP, 1993.

DE CAMPOS, H. (org.). Ideograma: lógica poesia linguagem. São Paulo: Editora Cultrix, 1993.

DELEUZE, G. Crítica e clínica. Tradução P. Pál Pelbart. São Paulo: Editora 34, 1997.

DERRIDA, J. A farmácia de Platão. Tradução R. da Costa. São Paulo: Ed. Iluminuras, 2005.

EHRENZWEIG, A. L'ordre caché de l'art. Essai sur la psychanalyse de l'imagination artistique. Trad. F. Lacoue-Labarthe e C. Nancy. Paris: Gallimard, 1974.

FENOLLOSA, E.;POUND, E. El caracter de la escritura china como medio poético. Tradução M. Antolin Rato. Madrid: Visor, 1977.

FRANCHETTI, P., DOI, Elza T.; DANTAS L. Haikai. Campinas: Editora da Unicamp, 1996.

FREUD, S. Vorlesungen zur Einführung in die Psychoanalyse und Neue Folge. Frankfurt am Main: Fischer, 1969. 
FRY, N. Fearful Symmetry: A Study of William Blake. Princeton: Princeton University Press, 1969.

HILST, H. わたしの犬の眼で. 猥藝な D 夫人 (Watashi no inu no manako. Waisetsuna D funin). Tradução I. Yomota. Tóquio: Gendaishicho, 2017.

NIETZSCHE, F. O Nascimento da tragédia. Tradução J. Guinsburg. São Paulo: Companhia das Letras, 2007.

WÖLFFLIN, H. Principes fondamentaux de l'histoire de l'art. Le problème de l'évolution du style dans l'Art Moderne. Tradução C., e M. Raymond. Paris: Plon, 1952. YOMOTA, I. (四方田犬彦). わが煉獄 (Waga rengoku). Yuigahama: Minato no hito, 2014.

YOMOTA, I. (四方田犬彦). My Purgatory. Tradução H. Sato. Winchester: Red Moon Press, 2015.

https://seriealfa.com/tigre/indextigre.htm Último acesso em 20 de dezembro de 2018. https://www.japandict.com

https://www.linguee.com/japanese-english/translation 